\title{
The Research of the Architectural Form and the House Style Design about the Small and Medium-sized Urban High-rise Residential Building Take Changchun as An Example
}

\author{
ZHANG meng ${ }^{1, a}$ \\ 1 Jilin Jianzhu University, Changchun 130000,China \\ a Zhangmeng918@yeah.net
}

Keywords: culture convergence; Architectural Form; Small and Medium Unit; High-rise Residential Building; Changchun city

\begin{abstract}
With regional advantage gradually revealed, expansion accelerated significantly in Changchun city, capital of Jilin. More and more living communities, residential buildings occupy urban or important occasions. Residential projects with the aid of modern technology and material, to the environment and the transformation of the social development into a large-scale revolution. High-rise residences are a kind of development and construction of city. Entering the new century, Changchun city has seen rapid promotion. Urban construction, especially the high-rise residences copy first-tier cities and even Europe and the United States, imitating some popular style.
\end{abstract}

\section{Introduction}

The culture is converging, and different habitation and theory is affected by the others. Urban construction, especially the high-rise residences copy first-tier cities and even Europe and the United States, imitate some popular style. According to the climate, geography and geographical environment of Changchun, as well as urban construction, culture and other social factors, Changchun strives to explore city development needs to meet the demands of citizens' usual design methods and ideas of high-rise residences so as to coordinate the relationship between residential environment and people This research object takes Changchun as example, bases on the territorial environment and social factors description, such as the climate, geography, urban construction, culture of Changchun and its current residential analysis, aims at exploring the design approaches and thoughts of small and medium sized high-rise residential buildings to be in line with the needs of Changchun's development and its citizens' comfortable living, and trying to demonstrate the future trend of small and medium sized high-rise residential buildings which is characterized by the harmony of "environment, Residential buildings and human" and meanwhile the regional characteristics, cultural and times spirits of Changchun. [1].

\section{Architectural Form}

China's accession to the world trade organization (WTO) marks China's formal entry into the world economy circulation, mutual harmony with the economic and cultural exchange to make national science and technology and cultural heritage the common wealth of people, so as to break each other segmentation state of multicenter, move towards the world synchronization integration process. The building as a culture, it is the economy, technology, philosophy, art elements such as organic synthesis, with space-time and region. At the same time, as a cultural ecological system, building, with the development of economy, the progress of science and technology, culture and information sharing improves, even in a certain period can be used as the carrier of regional culture and national culture refining and sublimation, widely recognized and accepted by the world, thus has been international.

Regional and national architectural culture under certain conditions can be converted into an international architectural culture, international architectural culture can also be absorbed, which is the fusion of new regional and national architectural culture.

The challenge came on December 11, 2001, when our country has formally become a member of the WTO. Accession to the WTO not only means that our country's economy will be integrated 
into the tide of world economy and other aspects, such as ideology will "be closely contacted" with the world. Especially in the field of culture, to join the world trade organization, means that China's social development in eastern and western culture collision and fusion. The diversity of culture is by far the human basic facts. The fact is so; because the cultural value system (as the realistic) nature has certain diversity. The modern western culture is a kind of strong culture, with strong penetration and attractive. After entering into the WTO, the east and west cultural fusion and conflict, can make the Oriental culture, especially Chinese traditional culture under the influence of foreign culture and assimilation, appearing the so-called "cultural convergence" phenomenon. Culture, has a variety of meaning [2].

\section{The House Design}

City high-rise residences, as a kind of residential building type, which is closely linked with the public in the form of the building (external) design should reflect history, spirit, culture and geographical features. That family planning layout should be "livable" is considered as the primary premise. Research purpose and meaning of the second quarter residence is the social, economic and cultural living body comprehensive reaction, in particular, in building the large categories, bearing the brunt of the housing to be the best reflection of age and social status. Under development in the new century, China city, small and medium-sized housing construction should be considered not only adapt to the environment (external) form, inheriting culture; At the same time, should respect the aspirations of people: family planning and full of human science and technology, low carbon life configuration. These have become important topic in today's urban high-rise residences design in our country.

In residential construction is increasingly emphasized by "humanism", "cultural heritage" and "environmental protection", the three major themes of today, the humanistic pursuit of residential and "pleasant" in the first place. Residential buildings, as the environment of mediation, especially urban high-rise residences: its construction (external) form shall be coordinated with city region, environment. Internal model should protect and respect for human life. Construction should always be around "person", and always emphasize the "form" and "family" harmonious dependence of two key factors. Study the city middle and small high-rise residential buildings (external) and the door model design, the first is based on the majority of the people of the "appropriate in life" vision, solve the city high-rise residences living brings happiness. Taking Changchun city as the concrete research field, and strive to explore, from the Angle of form and family multi-angle, wide dimension is analyzed. To help in the design of the city of high-rise residences, for our country city high-rise residences offer reference for the innovative research, and to bring some inspirations for the future sustainable development of the cause of the human settlements in China [3].

Since 1998 in our country gradually stopped the welfare of the housing distribution system. As the current situation, the development of residential construction speed is quick and the market is active. Geared to the needs of the broad masses of people of small and medium-sized residential demand is one of the biggest plan in our country in 2010 when the per capita housing area of $25 \mathrm{~m}^{2}$, 2010 worth of $80 \mathrm{~m}^{2}$. The most construction on the market at present is the kind of housing, economy applicable room by state policy support based on the standards for development and construction, which was welcomed by the masses of low-income families. Here refers to small and medium-sized residential that also occupy an residential area of $70 \mathrm{~m}^{2} \sim 70 \mathrm{~m}^{2}$. [4] Involved in are all aspects of residential design, including door model design, for small and medium-sized residential, more to the point. Under the influence of all kinds of disadvantageous factors, how to make small and medium-sized residential door model design is reasonable, achieve high quality and high comfort, we should attach importance to it and consider the following several aspects.

Here are two table of the suggested size residential main room 
Table 1.The size of residential main room studio suggested

\begin{tabular}{|l|l|l|l|l|l|}
\hline Room & living room & dining room & toilet master & bedroom & $\begin{array}{l}\text { subaltern } \\
\text { room }\end{array}$ \\
\hline size & $3.3 \sim 3.9$ & $2.1 \sim 2.4$ & $1.4 \sim 1.8$ & $3.3 \sim 3.6$ & $2.7 \sim 3.0$ \\
\hline
\end{tabular}

Table 2.The size of residential main room depth suggested

\begin{tabular}{|l|l|l|l|l|l|}
\hline Room & living room & dining room & toilet master & bedroom & $\begin{array}{l}\text { subaltern } \\
\text { room }\end{array}$ \\
\hline size & $3.9 \sim 4.2$ & $2.7 \sim 3.3$ & $2.1 \sim 2.4$ & $3.9 \sim 4.2$ & $3.0 \sim 3.3$ \\
\hline
\end{tabular}

1. According to various using objects, the residential design model should be diverse.

The design should take people's living requirement into consideration, though in the current situation, in most cities of our country the designation is hard to be typical, but with the development of the society, more family pattern will appear. As the housing commercialization, different combination forms of family will become more and more. Tailoring for residents will also be possible. Residents to participate in the design will be necessary.

In housing design, it should be considered that the house may have different function, newly designed leaving room for separation, combination, and increasing the adaptability of the residence, as convenient as the building blocks. Adapt to the needs of an aging society, both points and close the "two generations of house", a door is relatively important, separating two sets of housing, food, lay can not only care for the elderly, and to keep each other not be disturbed. China has gradually entered the aging society; the diversification of design is the inevitable trend. For small and medium-sized family, targeted design should be reflected in such aspects as space division, changing the main diversified, such as partition between sitting room the bedroom can press nonbearing wall design, so can close, as well as points for such as the use of single clan or SOHO clan groups. Again as wrong layer and double entry structure, although the traffic area increased, but the space is rich, and a clear distinction between public and private space, well suited to the tastes of young people. The change of the same family, wrong layer can meet different needs.

2. Attaches great importance to the partition of different function space reasonable decoration

After the housing situation of shortage in our country ended, people have more and higher requirement of comfort, housing design need more comfort in the division of functions. A good design of the housing layout, under the functions of residential space giving good care and thoughtful consideration, and the ability to change to the function is quite important. It makes the people that reside in the small area, feel very comfortable, also avoid unnecessary waste. [5]

For limited, collective small and medium-sized residential area, on the change of the space has the certain difficulty; some proper means can change the oppression and cramped space. The use of fuzzy space, some of the different functional spaces combined into one, also is a kind of effective method of small and medium-sized family to change space, the premise is to lose no their independent functions, such as sitting room and dining-room, bedroom and study or restaurant share, etc., often can have a more open space, and make the small and medium-sized family did not feel small, meeting the psychological and physiological requirements of "comfort"[6].

\section{Summary}

People are living in various residential designs. To adapt to the life, in line with the regional climate, inheriting the essence of culture, we should always adhere to the "people first" concept. To the harmony of environment, society, residential buildings and people are pursuing modern city 
residential development.

As a core part of the urban residential building type, high-rise residences in the future of urban residential building development is bound to occupy the important position in very long stage: the group using the style will occupy a larger proportion in the urban population, the market demand will also present growth trend. Senior middle and small residential design must update the concept; comply with higher standard and meet the market demand, and to provide a new, healthy way of living. Designers of residential design of the housing layout should be fully aware of the demands and the trend of the development of science and technology. This article tries to provide a reference for city high-rise residences design innovation, in order to realize the spirit of the pursuit of harmony living environment.

\section{Acknowledgements}

Jilin Provincial Department of Education, “12th Five-Year Plan” Social science research. No. 2012-469

\section{References}

[1] B.Georges, Skt High Living-Contemporary High-rise Apartment and Mixed-use Building [M]. Australia: The Images Publishing.Group pty ltd.2002.

[2] Jia Beisi, Adaptable Housing Or Adaptable People? [M], Architecture \& Comportment, 1995.

[3] Fanset, P.G. \& L.Colquhoom, Housing Design [M] .Editorial Gustavo Gill S.A.

[4] Lee, J.S.,Geology of gorge district of Yangtze(form Ichang to Tzekuei with reference to the development of gorges.Bull.Geol. Soc. of China,1925,vol.3)

[5] Knox P and Pinch S.Urban Social Geography-An Introduction[M]. 4 th ed. Englewood

CliffsNJ: Prentice Hall, 2000

[6] http://news.dichan.sina.com.cn/2011/08/22/361486.html 